\title{
A prospective study of risk factors for first trimester miscarriage in Asian women with threatened miscarriage
}

\author{
Leong Jin Kouk ${ }^{1}$, BSc, Ghim Hoe Neo ${ }^{1}$, MD, Rahul Malhotra ${ }^{1}, \mathrm{MD}, \mathrm{MPH}$, John Carson Allen ${ }^{2}$, PhD, \\ Suan Tiong $\underline{B e h}^{3}$, MBBS, MRCOG, Thiam Chye $\underline{T a n}^{3}$, MBBS, MMed, Truls $\underline{\emptyset \text { stbye }}{ }^{1,4}, \mathrm{MD}, \mathrm{PhD}$
}

INTRODUCTION The present study aimed to assess the demographic, socioeconomic, medical and lifestyle factors associated with the progression of a threatened miscarriage to a complete miscarriage in the first trimester.

METHODS A prospective cohort study was conducted on 157 women who presented with vaginal bleeding in the fifth to tenth week of gestation. Cox regression analysis was used to determine the risk factors for progression to a complete miscarriage within 16 weeks of gestation.

RESULTS Of the 139 women included for data analysis, 36 (25.9\%) had a miscarriage, mostly within two weeks of presentation. The results of our study showed that women aged $\geq 34$ years were more likely to miscarry (hazard ratio $[H R]=1.95)$. Compared to women whose partner was $20-30$ years of age, women whose partner was $\geq 41$ years of age also had a higher likelihood of experiencing a miscarriage $(H R=8.33)$. However, the presence of nausea $(H R=0.33)$ and a high stress score (i.e. $\geq 17)$ on the Perceived Stress Scale $(H R=0.49)$ were associated with a reduced likelihood of miscarriage.

CONCLUSION Older pregnant women experiencing a threatened miscarriage should be counselled about their higher risk of miscarriage, especially if they have an older partner.

Keywords: maternal age, nausea, paternal age, Southeastern Asia, threatened abortion

\section{INTRODUCTION}

Threatened miscarriage is a relatively common complication during pregnancy, occurring in approximately $20 \%$ of all pregnancies. ${ }^{(1,2)}$ Vaginal bleeding during the first trimester is associated with an approximate $5.5 \%-42.7 \%$ risk for subsequent complete miscarriage. ${ }^{(3-8)}$ Women who experience such bleeding, but do not experience a subsequent complete miscarriage, still have an increased risk for other adverse outcomes such as antepartum haemorrhage, preterm delivery, low birth weight and the possible need for assisted delivery. ${ }^{(9,10)}$

The risk factors for the progression of a normal pregnancy to a complete miscarriage in the first trimester are fairly well established. Common risk factors include increased maternal age, high pre-pregnancy body mass index (BMI) and low serum progesterone levels. ${ }^{(11-14)}$ More recently, lifestyle factors such as caffeine intake, ${ }^{(15)}$ exercise, ${ }^{(16)}$ stress, ${ }^{(9,17)}$ exposure to cigarette smoke, ${ }^{(18,19)}$ and alcohol consumption ${ }^{(12,20,21)}$ have also been implicated as risk factors. Some studies have documented the proportion of women who had experienced a threatened miscarriage who subsequently go on to experience a complete miscarriage. ${ }^{(4,6-8)}$ Surprisingly, however, little is known about the risk factors for the progression of a threatened miscarriage to a complete miscarriage. It is through the understanding of such risk factors that obstetricians would be better able to manage and advise women who are at high risk. A study conducted in Singapore in 1992 identified certain clinical and ultrasonographic factors associated with the progression of a threatened miscarriage to a complete miscarriage; these included maternal age, extent of vaginal bleeding, abdominal pain, gestational age at onset of bleeding, uterine size and fetal cardiac activity. ${ }^{(22)}$ However, the study employed a retrospective record-based design and therefore did not assess lifestyle factors as potential risk factors or adjust for potential confounders of the observed associations.

Thus, the objective of this prospective cohort study was to assess key demographic, socioeconomic, medical and lifestyle factors that predispose pregnant women who experience a threatened miscarriage within the fifth to tenth week of gestation to subsequent progression to a complete miscarriage within 16 weeks of gestation.

\section{METHODS}

Between November 2010 and February 2011, we enrolled 157 women who presented as emergency cases to the Obstetrics and Gynaecology Clinic at KK Women's and Children's Hospital $(\mathrm{KKH})$, Singapore, with a threatened miscarriage (defined as vaginal bleeding within the first 20 weeks of pregnancy $\left.{ }^{(23)}\right)$ in the fifth to tenth week of pregnancy. $\mathrm{KKH}$ is the largest tertiary women's and children's hospital in Singapore, accounting for approximately 12,000 of the 30,000

\footnotetext{
${ }^{1}$ Program in Health Services and Systems Research, ${ }^{2}$ Office of Clinical Sciences, Duke-NUS Graduate Medical School, ${ }^{3}$ Department of Obstetrics and Gynaecology, KK Women's and Children's Hospital, Singapore, ${ }^{4}$ Duke Global Health Institute, Duke University, Durham, USA

Correspondence: Prof Truls Østbye, Professor, Program in Health Services and Systems Research, Duke-NUS Graduate Medical School, 8 College Road, Singapore 169857. truls.ostbye@duke-nus.edu.sg
} 
births per year in Singapore. This study was approved by the SingHealth Centralised Institutional Review Board (CIRB Ref: 2010/620/D). It was also exempted from full review by the Duke University Health System Institutional Review Board.

Women who presented with vaginal bleeding during the fifth to tenth week of pregnancy, determined via ultrasonography, were included in the study. One reason for setting the upper limit of the gestational age as ten weeks for inclusion in the study was to maintain homogeneity with respect to the maternal hormonal environment, specifically the source of progesterone in the sample of women we enrolled, since it is known that the production of progesterone shifts from the corpus luteum to the placenta late in the first trimester. ${ }^{(24)}$ The second reason was that since the primary outcome was assessed at 16 weeks of gestation, curtailing inclusion at a gestational age of 10 weeks ensured a reasonably long follow-up period. The study excluded women with multiple pregnancies (as per ultrasonography), bleeding subsequent to a local pathology (e.g. a tear or a polyp) or an ectopic pregnancy. Among those who were enrolled, participants who electively terminated the of pregnancy, were lost to follow-up, or were subsequently found to have an ectopic pregnancy, were excluded from the data analysis.

All participants were interviewed only after they had been attended to by the managing doctor. Interviewers had no role in the management of the patients. After written informed consent was obtained, participants were interviewed using a questionnaire to collect data on demographic, socioeconomic, medical and lifestyle variables. The medical records of the women were also studied after consent was obtained, to supplement the data collected during the interview.

The following maternal factors were examined as potential risk factors for miscarriage: age $(<34$ years or $\geq 34$ years); marital status (married or single/divorced); ethnicity (Chinese, Malay, Indian or other); gestational age (wks) at presentation, determined by ultrasonography; educational level; housing (public or private); number of children; pre-pregnancy BMI $\left(\mathrm{kg} / \mathrm{m}^{2}\right)$; regularity of menstrual cycles; presence of nausea during pregnancy; history of miscarriage; history of termination of pregnancy; history of benign gynaecological conditions; smoking status; alcohol consumption; caffeine intake; mobile phone use (in hours per day); computer use (hrs/day); history of depression or schizophrenia; extent of bleeding (spotting, wet pad, single soaked pad or $>$ one pad soaked); and any prior episodes of vaginal bleeding during the current pregnancy. In addition, the age of the women's partners (20-30 years, 31-40 years or $\geq 41$ years) and smoking status of household members were also recorded.

The 10-item Perceived Stress Scale (PSS) designed by Cohen et $\mathrm{al}^{(25)}$ was used to measure the stress levels of the women in the one-month period preceding their presentation to the clinic. PSS is a measure of psychological stress; it assesses the extent to which respondents perceive the situations faced over the last month as stressful. It has been used to study the correlation between stress and various health conditions, ${ }^{(26-28)}$ and has been validated in different countries, including China and Japan. ${ }^{(29-32)}$ The scale was also previously used to assess stress levels among antenatal and postnatal populations. ${ }^{(33-39)}$ In the present study's analysis, the median score of the sample (i.e. 17 points) was used to demarcate the high- and low-stress groups.

The medical case records of the women who continued to receive care at $\mathrm{KKH}$ were used to determine their pregnancy status after the completion of the 16 weeks of gestation. Women who did not continue to receive care at $\mathrm{KKH}$ after enrollment were contacted via telephone after 16 weeks of gestation to determine their pregnancy status (i.e. whether they had experienced a complete miscarriage, and if so, when it had occurred).

Of the 157 participants enrolled, 11 were lost to follow-up, 4 had elective termination of pregnancy, 1 was subsequently found to have an ectopic pregnancy, 1 had a blighted ovum and 1 was found to have a gestation age of less than five weeks after ultrasonographic examination. After excluding these 18 women, a total of 139 participants were included for the data analysis. There were no significant differences in the distribution of the various potential risk factors between those included in the study $(\mathrm{n}=139)$ and those excluded $(n=18)$ from the analysis ( $p$-value $>0.05$, chi-square or Fisher's exact test).

Given the prospective nature of the study and the fact that the study participants contributed variable amounts of follow-up time, survival analysis was used to identify significant risk factors for miscarriage. The time-to-event variable used in the analysis was weeks in study and ranged from zero weeks (i.e. those who miscarried on the day of enrollment) to 11.9 weeks (i.e. those who were enrolled at five weeks gestation and had a viable pregnancy at the end of the follow-up period). Women were censored when they experienced a complete miscarriage or if they still had a viable pregnancy at the end of the follow-up period. The exact date of miscarriage was not available for four participants who experienced a miscarriage before 16 weeks. As such, their time to miscarriage was imputed as two weeks, based on the median time to miscarriage for the other women who experienced a miscarriage.

An overall Kaplan-Meier curve was first obtained to examine the pattern of miscarriage in the cohort. Following this, bivariate Cox regression analysis was used to assess the association of each risk factor with the risk of miscarriage, with gestational age at enrollment as a covariate in all the analyses. To select the significant risk factors from all the potential risk factors considered, stepwise Cox regression was performed, with the necessary inclusion of gestational age at enrollment as a covariate. The significant levels to enter and stay in the model were set at $p<0.10$. The factors selected by the stepwise model were then included in a multivariate Cox 
Table I. Potential risk factors for complete miscarriage among women experiencing a threatened miscarriage at $6-10$ weeks gestation ( $n=139)$ : distribution at baseline and bivariate association with complete miscarriage.

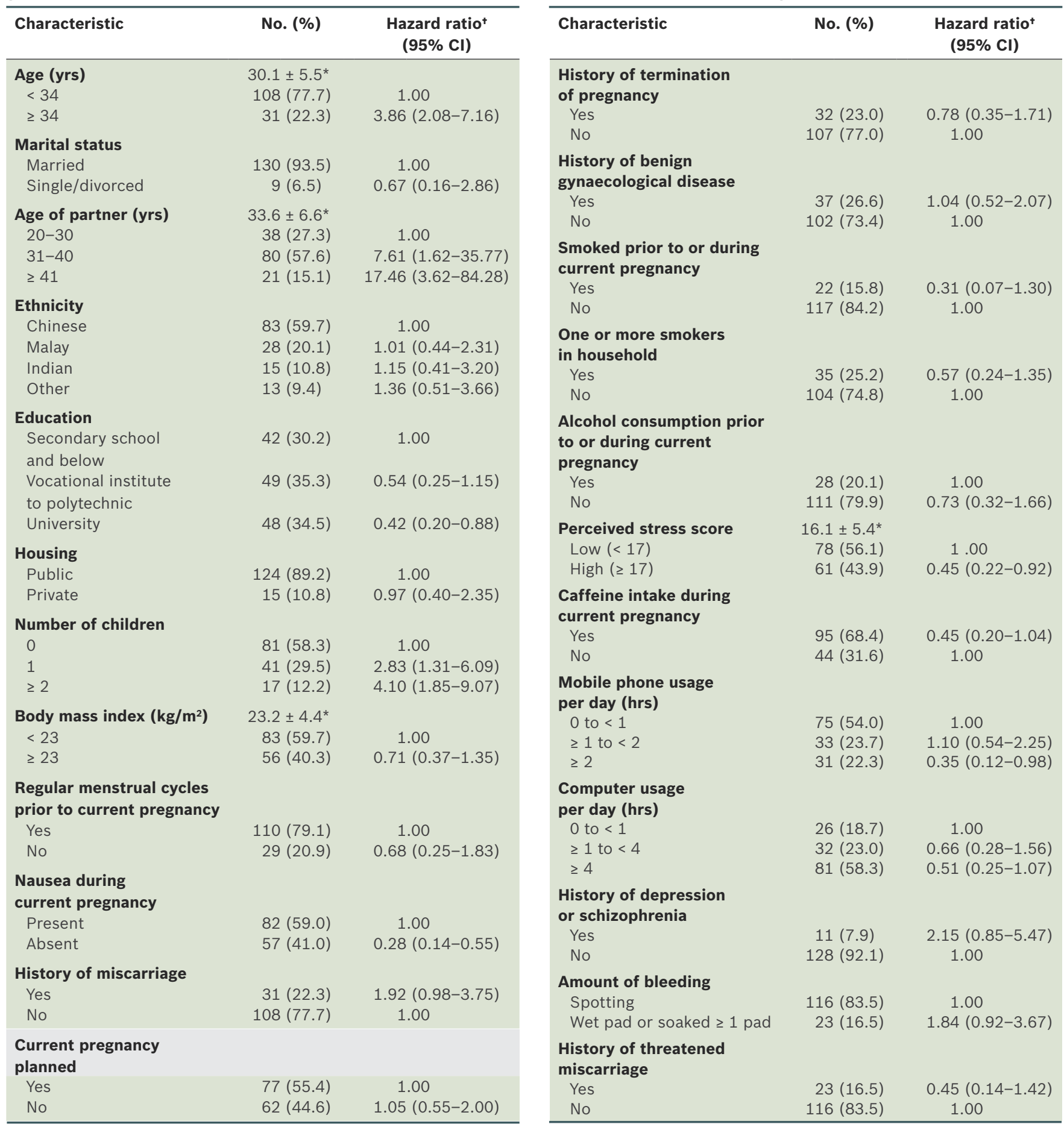

${ }^{*}$ Data is presented as mean \pm standard deviation. ${ }^{\dagger}$ Hazard ratio was adjusted for gestational age at baseline only. Cl: confidence interval

regression model, again with gestational age at enrollment included as a required variable. We checked and verified that the proportional hazard assumption was not violated for any of the predictor variables used in the multivariate Cox regression model. We also obtained unadjusted Kaplan-Meier curves for the factors that were found to be significant in the multivariate Cox regression model. Similar models with maternal and paternal ages as continuous variables were developed.

\section{RESULTS}

The average gestational age of the study participants at baseline was $6.9 \pm 1.5$ weeks. The distribution of the potential risk factors of the 139 women (i.e. the data analysis sample) at baseline is shown in Table I. Most participants were married, had no history of miscarriage or elective termination of pregnancy, and were nonsmokers and nondrinkers. Most also had no history of hypertension, thyroid dysfunction or diabetes mellitus; no history of psychiatric disease (i.e. depression 


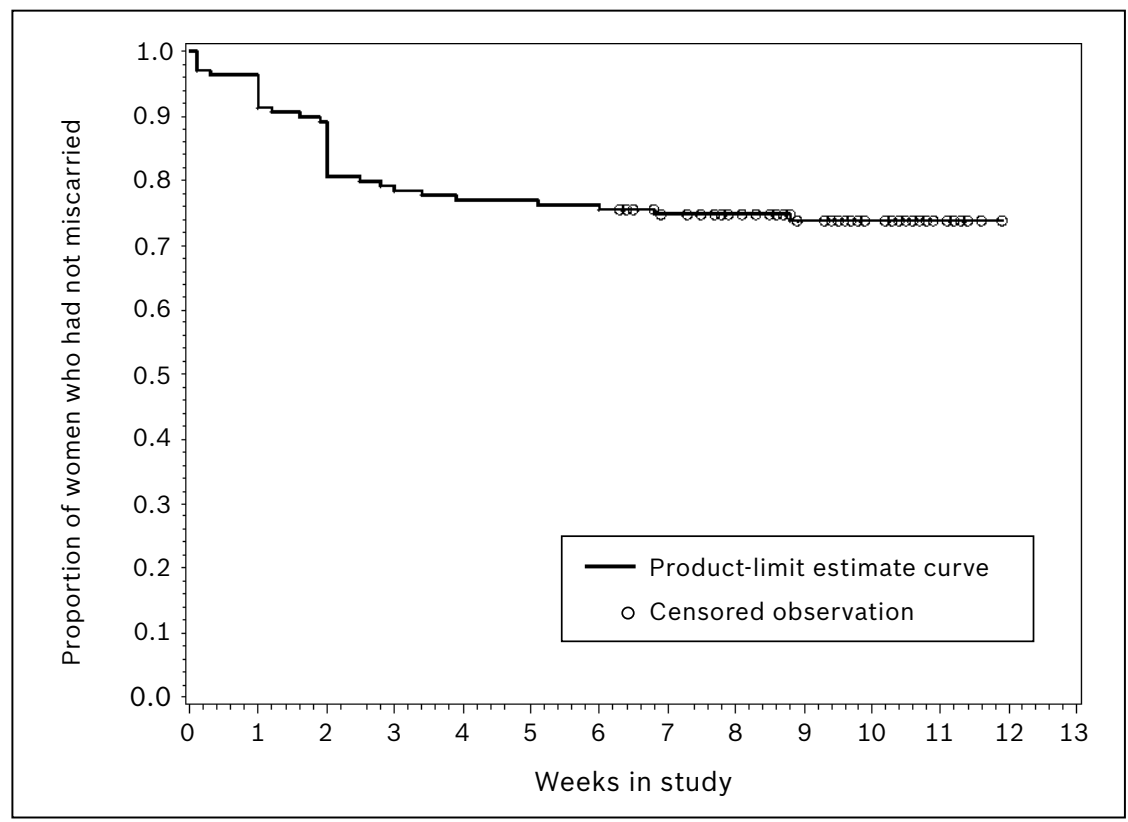

Fig. 1 Kaplan-Meier curve for the probability of maintaining pregnancy until the 16 th week of gestation.

Table II. Hazard ratios of the various risk factors from the multivariate Cox regression model.

\begin{tabular}{lcc}
\hline Parameter & HR & $\mathbf{9 5 \% ~} \mathbf{~ l ~}$ \\
\hline Gestational age (wks) & 0.77 & $0.56-1.06$ \\
Stress level (high vs. low) & 0.49 & $0.25-0.96$ \\
Age of partner (yrs) & & \\
$\quad$ 30-40 vs. 20-30 & 4.33 & $0.92-20.38$ \\
$\geq 41$ vs. 20-30 & 8.33 & $1.69-41.08$ \\
Nausea (present vs. absent) & 0.33 & $0.17-0.63$ \\
Maternal age (yrs) & & \\
$\quad \geq 34$ vs. < 34 & 1.95 & $1.02-3.73$ \\
\hline
\end{tabular}

Cl: confidence interval; HR: hazard ratio

and schizophrenia) and no other gynaecological problems. The majority of the women presented with spotting and experienced their first episode of bleeding in their current pregnancy. The mean PSS score was 16.1, with a median score of 17 . Within 16 weeks of gestation, 36 (25.9\%) of the 139 women progressed to a complete miscarriage. Most of the women who experienced a complete miscarriage did so within the first two weeks after presenting with a threatened miscarriage, as shown in the Kaplan-Meir survival curve (Fig. 1).

Bivariate analysis (Table I) showed that women aged $\geq 34$ years (relative to those who were younger), women whose partner was aged $\geq 31$ years (relative to those with a partner aged 20-30 years), and women with $\geq 1$ child had a greater likelihood of experiencing a miscarriage. Conversely, the presence of nausea during pregnancy, a PSS score $\geq 17$, mobile phone usage of over two hours per day and a university education were associated with reduced likelihood of miscarriage. In the final multivariate Cox regression model, maternal age $\geq 34$ years (hazard ratio $[H R]=1.95$ ) and paternal age $\geq 41$ years $(H R=8.33)$ remained significant risk factors for complete miscarriage after threatened miscarriage. Among the factors associated with a reduced likelihood for a miscarriage, only nausea ( $H R=0.33)$ and a PSS score of $\geq 17$ ( $\mathrm{HR}=0.49)$ remained significant (Table II).

We also developed an alternative model, which included maternal and paternal ages as continuous variables. In this model, the paternal and maternal ages were associated with an increased risk of miscarriage. Kaplan-Meier curves for the probability of maintaining pregnancy until the 16th week of gestation for the various categories of the four variables that were included in the multivariate model are shown in Fig. 2.

\section{DISCUSSION}

In this study, 36 (25.9\%) of the 139 women who experienced a threatened miscarriage progressed to a complete miscarriage within 16 weeks of gestation, consistent with the findings of some recently conducted studies. ${ }^{(3,5,40)}$ This percentage, however, is lower than that of the 1992 study conducted in Singapore, which reported that $55.3 \%$ of women who experienced a threatened miscarriage in the first trimester progressed to a complete miscarriage at any time during their pregnancy. ${ }^{(22)}$ The shorter follow up duration in our study, and possibly improvements in the management of threatened miscarriage over the years, may account for this discrepancy. In contrast, other studies have reported that less than $10 \%$ of women who experienced a threatened miscarriage progress to a complete miscarriage. ${ }^{(6-8)}$ However, these studies only included women with a viable fetus on ultrasonographic examination, which accounts for the low rate of progression to a complete miscarriage.

Women with a threatened miscarriage, but with no nausea, were found to be at a higher risk for a complete miscarriage than those who had experienced nausea. Nausea in the first trimester of pregnancy is associated with increased levels of beta human chorionic gonadotropin $(\beta-\mathrm{hCG}){ }^{(41,42)}$ and higher levels of $\beta$-hCG have been shown to be associated with a 

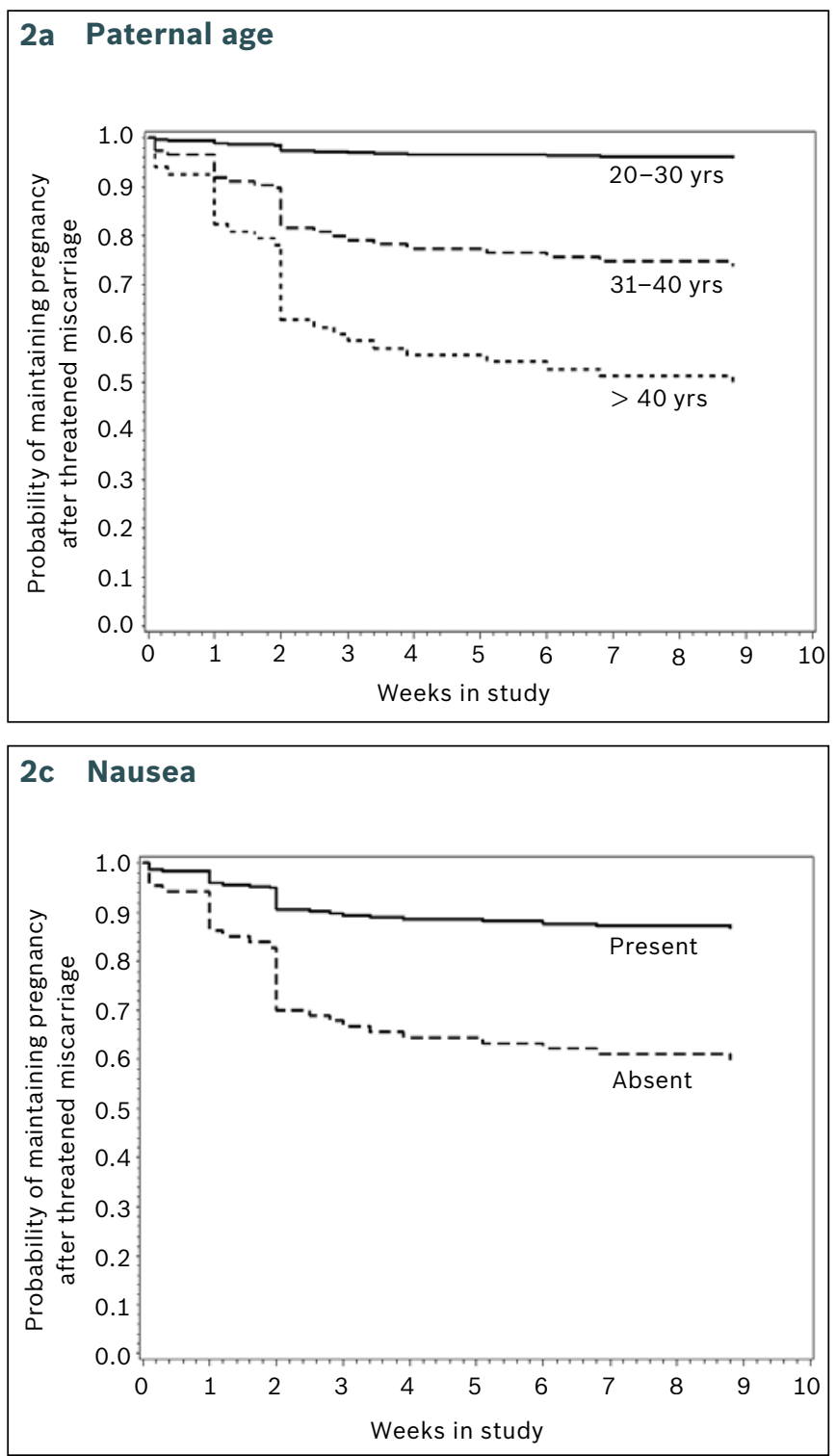

\section{2b Maternal age}

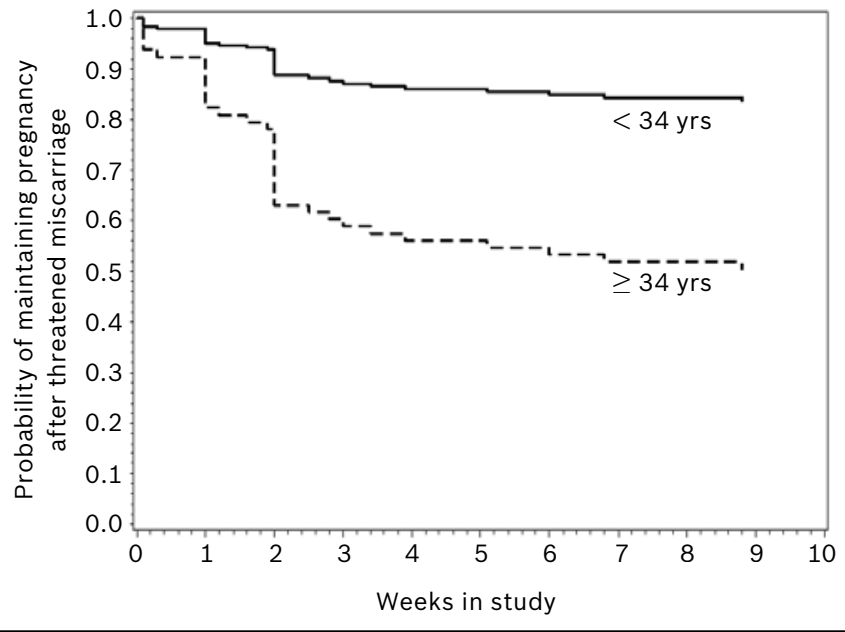

\section{2d Stress level}

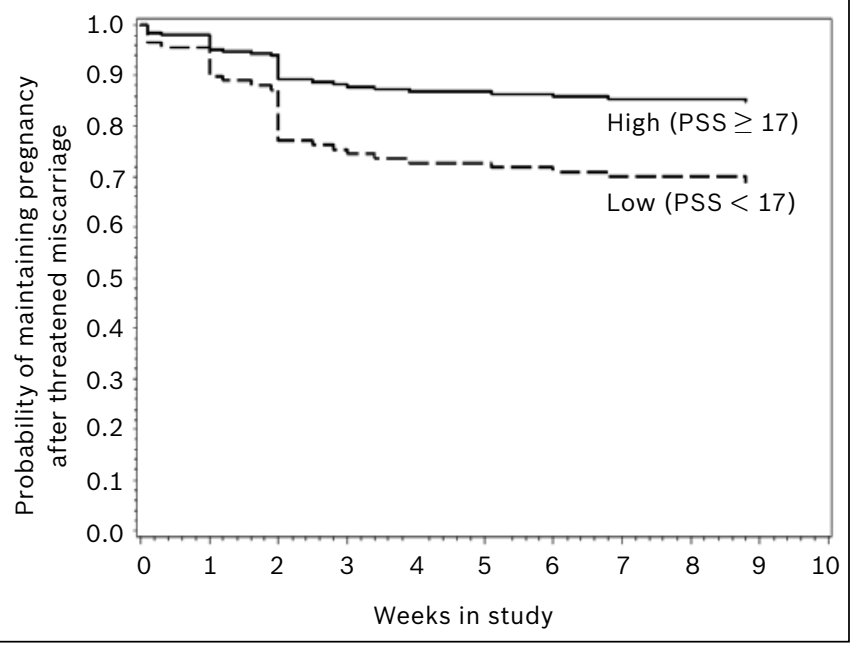

Fig. 2 Bivariate Kaplan-Meier curves for the various categories of the four variables included in the multivariate model.

decreased risk of miscarriage in normal pregnancies. ${ }^{(43,44)}$ Therefore, it is likely that the women who experienced nausea had higher levels of $\beta$-hCG, and were thus more likely to maintain their pregnancies after a threatened miscarriage.

Advanced maternal age was a significant risk factor for miscarriage in the group of women in the present study. Women aged $\geq 34$ years at presentation were more likely to have a complete miscarriage than women who were younger. This is consistent with previous studies, which showed that the risk of miscarriage is generally higher in pregnant women of greater age. ${ }^{(22,45,46)}$ The role of the age of the mother's partner on pregnancy outcome has not been as well demonstrated as the role of maternal age. Compared to women whose partner was aged 20-30 years, the risk of a complete miscarriage after a threatened miscarriage was 4.33 -fold higher for women with a partner aged 31-40 years, and 8.33-fold higher for those with a partner aged $\geq 41$ years. Other studies have also shown that the more advanced the age of the partner, the higher the risk of spontaneous miscarriage, especially in the first trimester of pregnancy. ${ }^{(46)}$ This has been attributed to decreased sperm quality and DNA changes in the sperm of older men. ${ }^{(47)}$ Studies have also shown that both the age of the mother and father are closely linked, and the advanced age of both parents is associated with a worse prognosis for the baby. ${ }^{(46)}$

No data for the general Singaporean women population, and for the pregnant Singaporean women population, is available for the purpose of comparison with the present study's mean PSS score. However, the present study's PSS mean score (i.e. 16.1) was significantly higher than the mean PSS score (i.e. 13.7) of community-dwelling women, obtained from the L. Harris poll conducted in the United States. ${ }^{(48)} \mathrm{A}$ likely explanation for the discrepancy is that women attending an emergency clinic for threatened miscarriage might be expected to experience higher levels of stress.

Within the present study, women who experienced more stress (i.e. had a PSS score of $\geq 17$ ) had a two-fold lower risk of miscarriage even after adjusting for significant risk factors. 
This was contrary to what we expected based on the existing literature. ${ }^{(12,17)}$ Stress is believed to increase the risk of miscarriage through the reduction of progesterone levels. ${ }^{(17)}$ A study showed that the effects of stress on miscarriage can be reversed with progesterone treatment. ${ }^{(49)}$ Since all the women in the present study were treated with progesterone supplementation, as per current standard of care for women with threatened miscarriage in $\mathrm{KKH}$, we speculate that the progesterone treatment might have negated the effects of stress on miscarriage.

No lifestyle or socioeconomic factors were identified as risk factors for complete miscarriage after threatened miscarriage in the adjusted analyses. However, this does not mean that lifestyle and socioeconomic factors are not important; it is possible that the present study was not adequately powered to detect whether these potentially weak risk factors were related to the outcome. Further studies with a larger number of participants will be necessary to determine the effect of these potential risk factors.

Most of the associations observed in the present study are consistent with similar studies conducted elsewhere, either among the general pregnant population or among pregnant women with threatened miscarriage. ${ }^{(22,41-46)}$ Most of the studies that assessed the risk factors for miscarriage have been retrospective. ${ }^{(12,42)}$ In contrast, the present study was prospective, thus reducing any recall bias with respect to the risk factors. The prospective nature of the present study also enabled better assessment of the causal direction, from the potential risk factors to the subsequent outcome of complete miscarriage. All the patients in the present study were attended to and assessed by obstetrics and gynaecology specialists in the clinic; interviewers had no role in the management of the patients. The study recruited both private and subsidised patients as the KKH Obstetrics and Gynaecology Clinic serves all obstetrics and gynaecology patients, irrespective of socioeconomic status.

A limitation of the present study is its relatively small sample size. While the sample was of sufficient size to enable stronger risk factors to be ascertained, it had less power to assess weaker risk factors. It is also important to highlight that all of the women in the present study were treated with progesterone supplementation, and thus the findings pertain only to women who receive progesterone treatment following a threatened miscarriage. While the instrument used to measure stress, i.e. PSS, has yet to be validated in Singapore, it has been validated in several countries ${ }^{(32,50)}$ and used in Singapore for different populations. ${ }^{(51,52)}$ Lack of comprehensive information on exposure to tobacco smoke, as well as alcohol and caffeine intake did not allow for quantification and detailed examination of the association of these variables with the risk of miscarriage. As previously discussed, the presence of nausea and PSS $\geq 17$ was associated with a decreased likelihood of complete miscarriage. The latter, which is counterintuitive, requires confirmation through further research, possibly using objective measures for assessing stress. While a number of potential risk factors were considered in the present study's analyses, other factors that can influence the risk of miscarriage, such as progesterone levels and fetal factors detected through ultrasonography, should be considered in future studies.

In conclusion, the present study showed that among women who experience an episode of threatened miscarriage in the fifth to tenth week of pregnancy, those aged 34 years or older, and whose partner is aged 41 years or older, have a greater likelihood of progressing to a complete miscarriage. While obstetricians do closely monitor women of advanced age, as they are at an increased risk of various antenatal complications, the findings of the present study suggest that older pregnant women who experience a threatened miscarriage should also be counselled about their higher risk of complete miscarriage, especially if they have an older partner.

\section{ACKNOWLEDGEMENTS}

This study was supported in part by the Obstetrics and Gynecology Society of Singapore Research Fund. The authors would like to acknowledge the support of Prof John Rush for his suggestions and input throughout the project, as well as the editorial assistance of Jon Kilner, MS, MA (Pittsburgh, PA, USA) and Ms Chandima Arambepola (Singapore).

\section{REFERENCES}

1. Everett $\mathrm{C}$. Incidence and outcome of bleeding before the 20th week of pregnancy: prospective study from general practice. BMJ 1997; 315: 32-4.

2. Weiss JL, Malone FD, Vidaver J, et al. Threatened abortion: A risk factor for poor pregnancy outcome, a population-based screening study. Am J Obstet Gynecol 2004; 190:745-50.

3. Basama FM, Crosfill F. The outcome of pregnancies in 182 women with threatened miscarriage. Arch Gynecol Obstet 2004; 270:86-90.

4. Davari-Tanha F, Shariat M, Kaveh M, Ebrahimi M, Jalalvand S. Threatened abortion: A risk factor for poor pregnancy outcome. Acta Med Iran 2008; 46:314-20.

5. El-Zibdeh MY, Yousef LT. Dydrogesterone support in threatened miscarriage. Maturitas 2009; 65 suppl 1: S43-6.

6. Tongsong T, Srisomboon J, Wanapirak C, et al. Pregnancy outcome of threatened abortion with demonstrable fetal cardiac activity: a cohort study. J Obstet Gynaecol (Tokyo 1995) 1995; 21:331-5.

7. Johns J, Hyett J, Jauniaux E. Obstetric outcome after threatened miscarriage with and without a hematoma on ultrasound. Obstet Gynecol 2003; 102:483-7.

8. Johns J, Jauniaux E. Threatened miscarriage as a predictor of obstetric outcome. Obstet Gynecol 2006; 107:845-50.

9. Wijesiriwardana A, Bhattacharya S, Shetty A, Smith N. Obstetric outcome in women with threatened miscarriage in the first trimester. Obstet Gynecol 2006; 107: 557-62.

10. Saraswat L, Bhattacharya S, Maheshwari A, Bhattacharya S. Maternal and perinatal outcome in women with threatened miscarriage in the first trimester: a systematic review. BJOG: 2010; 117:245-57.

11. Lashen H, Fear K, Sturdee DW. Obesity is associated with increased risk of first trimester and recurrent miscarriage: matched case-control study. Hum Reprod 2004; 19:1644-6.

12. Maconochie N, Doyle P, Prior S, Simmons R. Risk factors for first trimester miscarriage--results from a UK-population-based case-control study. BJOG 2007; 114:170-86.

13. Ong CY, Liao AW, Spencer K, Munim S, Nicolaides KH. First trimester maternal serum free beta human chorionic gonadotrophin and pregnancy associated plasma protein A as predictors of pregnancy complications. BJOG 2000; 107:1265-70. 
14. Sugiyama T, Watanabe $\mathrm{H}$, Takimoto $\mathrm{H}$, et al. Management of obesity in pregnancy. Curr Womens Health Rev 2009; 5:220-4.

15. Weng X, Odouli R, Li DK. Maternal caffeine consumption during pregnancy and the risk of miscarriage: a prospective cohort study. Am J Obstet Gynecol 2008; 198: 279.e1-8.

16. Madsen $M$, Jorgensen $T$, Jensen $M L$, et al. Leisure time physical exercise during pregnancy and the risk of miscarriage: a study within the Danish National Birth Cohort. BJOG 2007; 114:1419-26.

17. Arck PC, Rose M, Hertwig K, et al. Stress and immune mediators in miscarriage. Hum Reprod 2001; 16:1505-11.

18. George L, Granath F, Johansson AL, Annerén G, Cnattingius S. Environmental tobacco smoke and risk of spontaneous abortion. Epidemiology 2006; 17:500-5.

19. Venners SA, Wang $X$, Chen $C$, et al. Paternal smoking and pregnancy loss: a prospective study using a biomarker of pregnancy. Am J Epidemiol 2004; 159:993-1001.

20. Kesmodel U, Wisborg K, Olsen SF, Henriksen TB, Secher NJ. Moderate alcohol intake in pregnancy and the risk of spontaneous abortion. Alcohol Alcohol 2002; 37:87-92.

21. Windham GC, Fenster L, Swan SH. Moderate maternal and paternal alcohol consumption and the risk of spontaneous abortion. Epidemiology 1992; 3:364-70.

22. Han $\mathrm{HC}$, Tan $\mathrm{KH}$. A clinical study of the prognosis and outcome of first trimester threatened abortion. The Singapore Family Physician 1992; 18:35-44.

23. Sotiriadis A, Papatheodorou S, Makrydimas G. Threatened miscarriage: evaluation and management. BMJ 2004; 329:152-5.

24. Arck PC, Rücke M, Rose M, et al. Early risk factors for miscarriage: a prospective cohort study in pregnant women. Reprod Biomed Online 2008; 17:101-13.

25. Cohen S, Kamarck T, Mermelstein R. A global measure of perceived stress. J Health Soc Behav 1983; 24:385-96.

26. Cohen S, Lichtenstein E. Perceived stress, quitting smoking, and smoking relapse. Health Psychol 1990; 9:466-78.

27. Cohen S, Tyrrell DA, Smith AP. Psychological stress and susceptibility to the common cold. N Engl J Med 1991; 325:606-12.

28. Sellers RM, Caldwell CH, Schmeelk-Cone KH, Zimmerman MA. Racial identity, racial discrimination, perceived stress, and psychological distress among African American young adults. J Health Soc Behav 2003; 44:302-17.

29. Mimura C, Griffiths P. A Japanese version of the perceived stress scale: translation and preliminary test. Int J Nurs Stud 2004; 41:379-85.

30. Pbert L, Doerfler LA, DeCosimo D. An evaluation of the perceived stress scale in two clinical populations. J Psychopathol Behav Assess 1992; 14:363-75

31. Reis RS, Hino AA, Añez CR. Perceived stress scale: reliability and validity study in Brazil. J Health Psychol 2010; 15:107-14.

32. Leung DY, Lam TH, Chan SS. Three versions of Perceived Stress Scale: validation in a sample of Chinese cardiac patients who smoke. BMC Public Health 2010; 10:513.

33. Lau Y, Yin L. Maternal, obstetric variables, perceived stress and healthrelated quality of life among pregnant women in Macao, China. Midwifery 2011; 27:668-73.

34. Gao LL, Chan SW, Mao Q. Depression, perceived stress, and social support among first-time Chinese mothers and fathers in the postpartum period. Res Nurs Health 2009; 32:50-8.

35. Lu H, Zhu X, Hou R, et al. Chinese family adaptation during the postpartum period and its influencing factors: A questionnaire survey. Midwifery 2012; 28:222-7.

36. Keim SA, Daniels JL, Dole N, et al. A prospective study of maternal anxiety, perceived stress, and depressive symptoms in relation to infant cognitive development. Early Hum Dev 2011; 87:373-80.

37. Rondó PH, Ferreira RF, Nogueira F, et al. Maternal psychological stress and distress as predictors of low birth weight, prematurity and intrauterine growth retardation. Eur J Clin Nutr 2003; 57:266-72.

38. Glynn LM, Schetter CD, Hobel CI, Sandman CA. Pattern of perceived stress and anxiety in pregnancy predicts preterm birth. Health Psychol 2008; 27:43-51.

39. Vythilingum B, Geerts L, Fincham D, et al. Association between antenatal distress and uterine artery pulsatility index. Arch Womens Ment Health 2010; 13:359-64.

40. Omar MH, Mashita MK, Lim PS, Jamil MA. Dydrogesterone in threatened abortion: pregnancy outcome. J Steroid Biochem Mol Biol 2005; 97:421-5.

41. Goodwin TM, Hershman JM, Cole L. Increased concentration of the free beta-subunit of human chorionic gonadotropin in hyperemesis gravidarum. Acta Obstet Gynecol Scand 1994; 73:770-2.

42. Gracia CR, Sammel MD, Chittams J, et al. Risk factors for spontaneous abortion in early symptomatic first-trimester pregnancies. Obstet Gynecol 2005; 106:993-9.

43. Furneaux EC, Langley-Evans AJ, Langley-Evans SC. Nausea and vomiting of pregnancy: endocrine basis and contribution to pregnancy outcome. Obstet Gynecol Surv 2001; 56:775-82.

44. Yaron Y, Ochshorn Y, Heifetz S, et al. First trimester maternal serum free human chorionic gonadotropin as a predictor of adverse pregnancy outcome. Fetal Diagn Ther 2002; 17:352-6.

45. Cleary-Goldman J, Malone FD, Vidaver J, et al. Impact of maternal age on obstetric outcome. Obstet Gynecol 2005; 105:983-90.

46. de la Rochebrochard E, Thonneau P. Paternal age and maternal age are risk factors for miscarriage; results of a multicentre European study. Hum Reprod 2002; 17:1649-56.

47. de La Rochebrochard E, Thonneau P. Paternal age >or $=40$ years: an important risk factor for infertility. Am J Obstet Gynecol 2003; 189:901-5.

48. Cohen S. Perceived stress in a probability sample of the United States. In: Spacapan S, Oskamp S, eds. The social psychology of health. CA: Sage Publications, 1988: p.31-67.

49. Kalinka J, Szekeres-Bartho J. The impact of dydrogesterone supplementation on hormonal profile and progesterone-induced blocking factor concentrations in women with threatened abortion. Am J Reprod Immunol 2005; 53:166-71.

50. Mimura C, Griffiths P. A Japanese version of the Perceived Stress Scale: crosscultural translation and equivalence assessment. BMC Psychiatry 2008; 8:85

51. Lok CF, Bishop GD. Emotion control, stress, and health. Psychol Health 1999; 14:813-27.

52. Lee KM, Manning V, Teoh HC, et al. Stress-coping morbidity among family members of addiction patients in Singapore. Drug Alcohol Rev 2011; 30:441-7. 